\title{
PENGARUH PENGGUNAAN MODEL $S A V I$ TERHADAP KETERAMPILAN MENULIS TEKS EKSPLANASI PADA SISWA KELAS XI SMA NEGERI 10 KABUPATEN TEBO
}

\author{
Erlina Zahar ${ }^{1}$, Muhd. Marwan Destian ${ }^{2}$ \\ Program Studi Pendidikan Bahasa dan Sastra Indonesia, \\ Fakultas Keguruan dan Ilmu Pendidikan, Universitas Batanghari, \\ Jambi \\ Erlina_zahar@yahoo.com \\ Marwandestian1@gmail.com
}

\begin{abstract}
The purpose of this research is to describe the influence of using Savi learning model on writing explanatory text for class XI students of SMA Negeri 10 Kabupaten Tebo. The method used in this research is quasy-experimental. In this research, 2 classes were used, namely the XI IPS 2 class control class which consists of 18 students and the XI IPS 1 the experimental class which also consists of 18 students. The requirements test that is carried out is the normality test and the homogeneity test. The results of the normality test for the experimental class are 0.24>0.05 and for the control class are 0.78>0.05. It means that the data are normal. The homogeneity test results is $0.661>0.05$ which means that the data are homogeneous. Thus the hypothesis can be tested. Hypothesis testing is done using the $t$-test formula. The results of this research indicate that the value of $t=3.633$ is higher than t table $=2.024$. It can be concluded that there is an influence of using the Savi model on the learning outcomes of writing explanatory text for class XI students of SMA Negeri 10 Kabupaten Regency. The average value of the experimental class is 79.72, which was higher than the control class value of 60.56 .
\end{abstract}

Keywords: influence, Savi model, writing explanatory text

\footnotetext{
${ }^{1}$ Dosen Program Studi Pendidikan Bahasa dan Sastra Indonesia, fakultas Keguruan dan Ilmu Pendidikan, Universitas Batanghari, Jambi

${ }^{2}$ Mahasiswa Program Studi Pendidikan Bahasa dan Sastra Indonesia, fakultas Keguruan dan Ilmu Pendidikan, Universitas Batanghari, Jambi
} 


\section{PENDAHULUAN}

Pendidikan merupakan salah satu usaha manusia untuk menumbuhkan dan mengembangkan potensi-potensi pembawaan baik jasmani maupun rohani sesuai dengan nilai-nilai yang ada dalam masyarakat dan kebudayaan (Ihsan, 2005: 1). Pendidikan juga bisa dikatakan dengan suatu usaha sadar yang dilakukan secara sistematis dalam mewujudkan proses pembelajaran agar peserta didik dapat mengembangkan potensi dirinya. Salah satu potensi yang dimiliki peserta didik adalah kemampuan berbahasa yang menjadi salah satu pembelajaran pada mata pelajaran Bahasa Indonesia. Mata pelajaran Bahasa Indonesia merupakan salah satu mata pelajaran yang mengarahkan siswa untuk berkomunikasi dalam bahasa Indonesia dengan baik dan benar, baik secara lisan maupun tulisan. Pelajaran Bahasa Indonesia mencakup empat aspek keterampilan, yaitu keterampilan menyimak, berbicara, membaca, dan menulis.

Pembelajaran Bahasa Indonesia di sekolah menuntut siswa agar mampu menguasai empat aspek berbahasa tersebut, Salah satunya keterampilan menulis. Rofii dkk. (2019A) mengatakan "Writing skill is one of four language skills that must be mastered by students" (keterampilan menulis merupakan salah satu dari empat keterampilan berbahasa yang harus dikuasai oleh siswa.

Berbagai macam materi pembelajaran dalam pembelajaran keterampilan menulis diantaranya menulis teks aditorial, teks eksposisi, teks anekdot dan teks eksplanasi. Teks eksplanasi merupakan teks yang berisi penjelasan tentang proses yang berhubungan dengan fenomena alam, sosial, dan budaya secara ilmiah (Priyanti, 2014: 82). Kejadian atau peristiwa yang terjadi di sekitar kita pantasnya tidak hanya kita amati saja serta dirasakan saja, tetapi sekaligus digunakan sebagai pembelajaran.

Keterampilan menulis teks eksplanasi diajarkan di Sekolah Menengah Atas (SMA) yang terdapat pada kurikulum 2013 kelas XI dengan kompetensi dasar (4.4) memproduksi teks eksplanasi secara lisan maupun tulisan dengan memperhatikan struktur kebahasaan. Pembelajaran tersebut bertujuan agar siswa mampu menulis teks eksplanasi dengan baik sesuai dengan kaidah dan struktur kebahasaan. Agar proses pembelajaran bisa tersampaikan dengan baik, maka dibutuhkan model pembelajaran yang sesuai.

Memilih model pembelajaran yang tepat dan sesuai dengan materi yang diajarkan sangatlah penting. Rofii, Murtadho, dan Rahmat (2019 C) yang mengatakan bahwa salah satu upaya yang dapat digunakan untuk mewujudkan pembelajaran efektif dalam mengoptimalkan hasil belajar, yakni dengan cara menggunakan model pembelajaran. Model pembelajaran yang sesuai dapat membangkitkan minat belajar siswa, dengan model yang tepat pelajaran yang diajarkan menjadi tidak monoton atau membosankan. Model pembelajaran yang menarik akan menjadikan proses pembelajaran efektif dan hasil belajar siswa menjadi lebih baik. Keberhasilan proses pembelajaran di kelas tidak terlepas dari kemampuan guru dalam mengembangkan model- 
model pembelajaran. Salah satu faktor yang mempengaruhi hasil belajar adalah model pembelajaran. agar tercapainya hasil pembelajaran maka penulis menawarkan model SAVI dalam pembelajaran menulis teks eksplanasi di SMA Negeri 10 Kabupaten Tebo.

Rofii, Murtadho, dan Rahmat (2019 B) mengatakan "The learning model is a guide for teachers planning learning activities in the classroom, starting from preparing learning devices, choosing media and tools, to evaluation tools that lead to achieve the objectives of thelesson" (model pembelajaran adalah pedoman bagi guru yang merencanakan kegiatan pembelajaran di kelas, dimulai dari mempersiapkan pembelajaran perangkat, memilih media dan alat, hingga alat evaluasi yang mengarah untuk mencapai tujuan pelajaran.. Model pembelajaran Savi merupakan model pembelajaran yang menggabungkan gerak fisik dengan aktivitas intelektual dan menggunakan semua indera yang dapat berpengaruh besar terhadap pembelajaran (Meier, 2004:91). Secara keseluruhan model pembelajaran somatic, auditory, visual, dan intellectual (SAVI) ini dapat digunakan sebagai alternatif model pembelajaran dalam pembelajaran kemampuan menulis teks eksplanasi. Model SAVI dapat meningkatkan aktivitas intellectual siswa agar mempunyai kemampuan dalam menungkan ide, pikiran pengalaman, dan pendapat yang benar.

Model pembelajaran Savi ini digunakan dalam pembelajaran menulis teks eksplanasi dikarenakan dengan model pembelajaran ini diasumsikan bahwa para siswa mampu mengoptimalkan semua kemampuan dan indera nya untuk memahami fenomena alam dan sosial, sehingga siswa mampu mengeluarkan gagasan dan pikirannya terhadap fenomena tersebut. Selain itu model Savi juga dianggap mempermudah siswa menulis teks eksplanasi secara baik.

Berdasarkan latar belakang tersebut, maka tujuan penelitian ini adalah untuk mendeskripsikan pengaruh penggunaan model pembelajaran Savi terhadap keterampilan menulis teks eksplanasi siswa kelas XI SMA Negeri 10 Kabupaten Tebo tahun pelajaran 2019/2020.

Penelitian ini diharapkan bermanfaat untuk mengembangkan teori pembelajaran, sehingga dapat memperbaiki mutu pendidikan dan meningkatkan kualitas pembelajaran. Penggunaan model pembelajaran Savi dalam pembelajaran menulis teks eksplanasi memberikan pilihan yang menarik bagi guru Bahasa Indonesia dalam memilih model pembelajaran serta dapat membantu meningkatkan minat belajar siswa.

Secara praktis, hasil penelitian ini diharapkan bermanfaat bagi berbagai pihak, di antaranya, sebagai berikut.

1. Bagi guru, hasil penelitian ini dapat dijadikan pertimbangan dalam memilih model pembelajaran yang sesuai dan menarik bagi siswa.

2. Bagi siswa, hasil penelitian ini diharapakan dapat menambah motivasi belajar. 
3. Bagi penulis, hasil dpenelitian ini apat menambah pengalaman berharga dan wawasan, terutama untuk memahami teks eksplanasi dan model-model pembelajaran.

4. Bagi peneliti lanjutan, hasil penelitian ini dapat dijadikan dasar pemikiran dalam melakukan penelitian lain dengan materi dan model pembelajaran yang berbeda.

\section{Kajian Teoretik}

Proses pembelajaran yang baik sangat tergantung pada motivasi siswa dan kreatifitas guru. Murid yang memiliki motivasi tinggi ditunjang dengan guru yang mampu memfasilitasi motivasi tersebut akan membawa siswa pada keberhasilan dan pencapaian target belajar. Pembelajaran merupakan proses yang direncanakan guru untuk mencapai tujuan belajar. Penyediaan sumber belajar secara terperogram dalam desain yang intruksional akan menjadikan pembelajaran menjadi lebih menarik, sehingga siswa lebih aktif dalam proses pembelajaran (Damiyati dan Mudjiono, 2013: 62). Dengan demikian, proses pembelajaran yang baik merupakan kegiatan yang dirancang agar proses pembelajaran menjadi lebih menarik. Keterampilan menulis menjadi salah satu keterampilan berbahasa yang dipelajari di sekolah. menulis merupakan suatu kegiatan untuk bersosialisasi dan menuangkan gagasan dan ide melalui ketepatan bahasa dan kosakata dengan baik melalui tulisan. Untuk membantu siswa belajar dengan baik, maka dibutuhkan proses pembelajaran yang baik pula (Faturrohman, 2015:16). Dengan demikian, dalam pembelajaran diperlukan proses yang melibatkan komunikasi multi arah, antara siswa dan peserta guru serta bahan ajar.

Keterampilan menulis menjadi salah satu keterampilan berbahasa yang dipelajari di sekolah. Salah satu cara mengunggkapkan pendapat, gagasan, dan perasaan juga bisa diungkapkan dengan bahasa tulis (Abbas, 2006: 125). Keterampilan menulis memiliki peran yang penting bagi siswa yang selalu dituntut untuk selalu bersosialisai.

Keterampilan menulis merupakan sebuah proses menyampaikan pesan atau informasi dengan bahasa tulis sebagai salah satu medianya merupakan keterampilan menulis (Dalman, 2013:3). Writing is a complex activity requiring extensive and comprehensive knowledge (Menulis adalah suatu kegiatan kompleks yang membutuhkan ekstensif dan pengetahuan yang komprehensif) (Rofii dkk. (2018: 51). Keterampilan menulis diajarkan dengan tujuan agar siswa mempunyai kemampuan dalam menuangkan gagasan dan ide dengan baik dan benar.

Keterampilan menulis memiliki tujuan objektif yang dapat dipertanggung jawabkan dihadapan para pembacanya, karena pada dasarnya tulisan adalah sarana untuk menyampaikan pendapat atau gagasan agar dapat dipahami dan diterima oleh orang lain. Adapun tujuan penulisan tersebut adalah sebagai berikut (Depdiknas, 2009:6).

1. Menginformasikan segala sesuatu, baik itu fakta, data maupun peristiwa termasuk pendapat dan pandangan terhadap fakta, dan data khalayak pembaca memperoleh pengetahuan 
dan pemahaman baru tentang berbagai hal yang dapat maupun yang terjadi di muka bumi ini.

2. Membujuk, melalui tulisan seorang penulisan mengharapkan pula pembaca dapat menentukan sikap, pakah menyetujui atau mendukung yang dikemukakan. Peulis harus mampu membujuk dan meyakinkan pembaca dengan menggunakan gaya persuasif. Oleh karena itu, fungsi persuasi dari sebuah tulisan akan dapat menghasilkan apabila penulis mampu menyajikan dengan gaya bahasa yang menarik, akrab, bersahabat, dan mudah dicerna.

3. Mendidik adalah salah satu tujuan dari komunikasi melalui tulisan. Melalui pembaca hasil tulisan wawasan pengetahuan sesorang akan terus bertambah, kecerdasaan akan terus diasah, yang pada akhirnya akan memnetukan perilaku seseorang. Orang-orang yang berpendidikan cenderung lebih terbuka dan penuh toleransi, lebih menghargai pendapat orang lain, dan tentu saja akan cenderung lebih rasional.

4. Menghibur, fungsi dan tujuan menghibur dalam komunikasi bukan monopoli media massa, radio, televisi, namun media cetak dapat pula berperan dalam menghibur khalayak pembacanya. Tulisan-tulisan dan bacaan-bacaan yang ringan, cerita dan pengalaman lucu bisa pula menjadi bacaan pelipur lara atau melepaskan ketegangan setelah seharian sibuk beraktivitas.

Pembelajaraan keterampilan menulis teks eksplanasi menjadi salah satu materi pembelajaran pada mata pelajaran Bahasa Indonesia pada jenjang Sekolah Menengah Atas (SMA). Pembelajaran menulis teks eksplanasi terdapat pada kurikulum 2013 yang dapat ditemukan pada materi kelas XI di Sekolah Menenengah Atas (SMA). Pembelajaran menulis teks eksplanasi sangat bermanfaat jika semua kompetensi dasar dalam pembelajaran menulis teks eksplanasi sesuai dengan buku lembar kerja siswa yaitu: (3.3) mengidentifikasi informasi dalam teks eksplanasi lisan dan tulisan. (3.4) menganalisa struktur dan kebahasaan teks eksplanasi. (4.3) mengkonstruksi informasi dalam teks eksplansi secara lisan dan tulisan. (4.4) memproduksi teks eksplanasi secara lisan atau tulisan memerhatikan struktur dan kebahasaan. Teks eksplanasi merupakan teks yang menjelaskan fenomena yang terjadi. Teks eksplanasi mempunyai fungsi sosial yang menjelaskan proses terjdinya sesuatu menurut prinsip sebab akibat (Kemendikbud, 2013:1).

Sebab akibat sebuah peristiwa dapat dijelaskan di dalam teks eksplanasi. Fenomena alam ataupun sosial dapat diterangkan dan dijelaskan di dalam teks eksplanasi (Kosasih, 2017:8). Dengan kata lain teks eksplanasi menjelaskan hubungan logis proses terjadinya suatu fenomena alam ataupun fenomena sosial. Di dalam teks eksplanasi juga dijelaskan secara bertahap berdasarkan hubungan logis sebab akibat (Darmawati, 2019:2). Oleh karena itu, teks eksplanasi memiliki fungsi menjelaskan mengapa dan bagaimana terjadi suatu fenomena. Baik alam maupun sosial, sehingga para pembaca teks eksplanasi bertambah pengetahuan.

Teks eksplanasi memiliki ciri kebahsaan yang menggunakan tiga kategori yaitu nomina, konjungsi dan verba. Hal ini untuk menunjukan sebab 
akibat yang dijelaskan di dalam teks eksplanasi.memahami ciri kebahasaan teks eksplanasi tentu akan mempermudah siswa dalam memahami teks eksplanasi. Menurut Darmawati (2018:22) ciri bahasa teks eksplanasi relatif berbeda dengan teks lainnya. Ciri-ciri bahasa yang dimaksud adalah sebagai berikut.

1. Menggunakan konjungsi kausalitas, diantaranya sebab, karena, oleh sebab itu, oleh karena itu, sehingga.

2. Menggunakan konjungsi kronologis (hubungan waktu), seperti kemudian, lalu, setelah itu, pada akhirnya.

3. Menggunakan kata benda yang merujuk pada jenis fenomena, bukannya pada kata ganti penceritaan.

4. Di dalam teks banyak dijumpai kata istilah sesuai dengan topik yang dibahas.

Ada begitu banyak model pembelajaran yang dapat digunakan dalam proses pembelajaran menulis teks eksplanasi. Salah satunya model pembelajaran yang dapat digunakan adalah model Savi. Model pembelajaran Savi adalah model pembelajaran yang menekankan pada peserta didik untuk mengkombinasikan seluruh alat indra yang didmiliki dengan kemampuan intelektual dalam aktivitas belajar. Menurut Huda (2016:283) model pembelajaran Savi adalah somatic, auditory, visualization dan intellctualy yang pertama kali diperkenalkan oleh David Meier yang merupakan seseorang pendidik dan trainer. Dengan memanfaatkan semua indera yang dimiliki oleh siswa, maka akan tercapai tujuan pembelajaran yang akan dinginkan.

Model pembelajaran Savi merupakan salah satu sarana untuk mencapai tujuan pembelajaran. Suherman (2002:52) berpandangan konsep pembelajaran Savi menuntut siswa agar mampu lebih aktif dalam proses pembelajaran, sehingga mampu meningkatkan hasil belajar siswa. Dengan demikian, model pembelajaran Savi bisa menjadi salah satu solusi untuk menunjang keberhasilan suatu pembelajaran.

\section{METODE PENELITIAN}

Penelitian ini dilakukan dengan menggunakan metode quasi eksperiment (eksperimen semu). Arikunto (2014: 207). berpandangan penelitian murni yang tidak harus memenuhi seleruh persyaratan disebut quasi eksperiment. Penelitian ini bertujuan mengungkapkan hubungan sebab akibat dengan cara melibatkan kelompok kontrol dan kelompok eksperimen. Menurut Sugiyono (2014:114) di dalam penelitian eksperimen, kelompok kontrol tidak mempunyai fungsi untuk mempengaruhi variabel-variabel luar terhadap pelaksanaan eksperimen.

Pendekatan yang digunakan dalam penelitian ini adalah pendekatan kuantitatif. Hasil perhitungan tersebut nantinya akan digunakan untuk menjawab tujuan penelitian yang meneliti dampak yang terjadi setelah adanya perlakuan terhadap peserta didik yang diajar menggunakan model Savi dan peserta didik yang diajar menggunakan model konvensional. 
Adapun populasi dalam penelitian ini adalah keseluruhan siswa kelas XI SMA Negeri 10 Kabupaten Tebo Tahun pelajran 2019/2020.

Dalam penelitian sampel diambil dengan purposive sampling. Purposiv sampling merupakan pengambilan sampel sumber data dengan pertimbangan tertentu (Sugiyono, 2014: 85). Dengan demikian sampel yang digunakan adalah kelas XI IPS 1 sebagai kelas eksperimen dan kelas XI IPS 2 sebagai kelas kontrol. Alasan kelas tersebut dijadikan sampel penelitian dikarenakan kelas tersebut memiliki karakteristik yang sama dan diajar oleh guru yang sama.

Dalam penelitian ini terdapat dua variabel, yaitu variabel bebas dan variabel terikat. "Variabel bebas adalah variabel yang mempengaruhi atau yang menjadi sebab perubahannya atau timbulnya variabel terikat" (Sugiyono, 2014: 61). Dalam penelitian ini yang menjadi variabel bebas yaitu penggunaan model pembelajaran Savi. "Variabel terikat adalah variabel yang dipengaruhi atau yang menjadi akibat, karena adanya variabel bebas" (Sugiyono, 2014: 39). Dalam penelitian ini yang menjadi variabel terikat yaitu keteampilan menulis teks eksplanasi.

Desain penelitian yang digunakan dalam penelitian ini adalah post-test dengan dua kelompok subjek, yaitu kelompok kontrol dan kelompok eksperimen. Pada kelompok eksperimen diberi perlakuan atau treatmen $(\mathrm{X})$ dan pada kelompok kontrol tidak diberi perlakuan atau treatmen (-).

Teknik pengumpulan data pada penelitian ini adalah dengan menggunakan penugasan. Penugasam dilakukan setelah berakhirnya serangkaian pembelajaran yang dilakukan. Pada kelas eksperimen menggunakan model pembelajaran Savi dan kelas kontrol menggunakan model pembelajaran konvensional. Teknik analisis data merupakan tahapan untuk menguji kebenaran hipotesis yang dilakukan dalam penelitian ini. Sebelum analisis dilakukan terlebih dahulu diajukan uji normalitas dan uji homogenitas.

\section{HASIL DAN PEMBAHASAN}

Setelah dilakukan proses penelitian, maka dapat deskripsikan hasil penelitian sebagai berikut. Penelitian ini dilakukan di SMA Negeri 10 Kabupaten Tebo pada kelas XI IPS 1 sebagai kelas eksperimen dan kelas XI IPS 2 sebagai kelas kontrol. Untuk penelitian di kelas eksperimen dilaksanakan pada tanggal 24 Februari 2020 dan untuk kelas kontrol dilaksanakan pada tanggal 25 Februari 2020. Pada proses pembelajaran, kedua kelas diberikan perlakuan yang berbeda. Pada kelas XI IPS 1 sebagai kelas eksperimen pembelajaran menggunakan model pembelajaran SAVI. Sedangkan kelas XI IPS 2 sebagai kelas kontrol pembelajaran menggunakan model pembelajaran konvensional atau tanpa model. Perbedaan nilai kelas eksperimen dan kelas kontrol dapat dilihat pada tabel berikut ini. 
Tabel 1. Perolehan Nilai Mahasiswa dalam Menulis Teks Eksplanasi

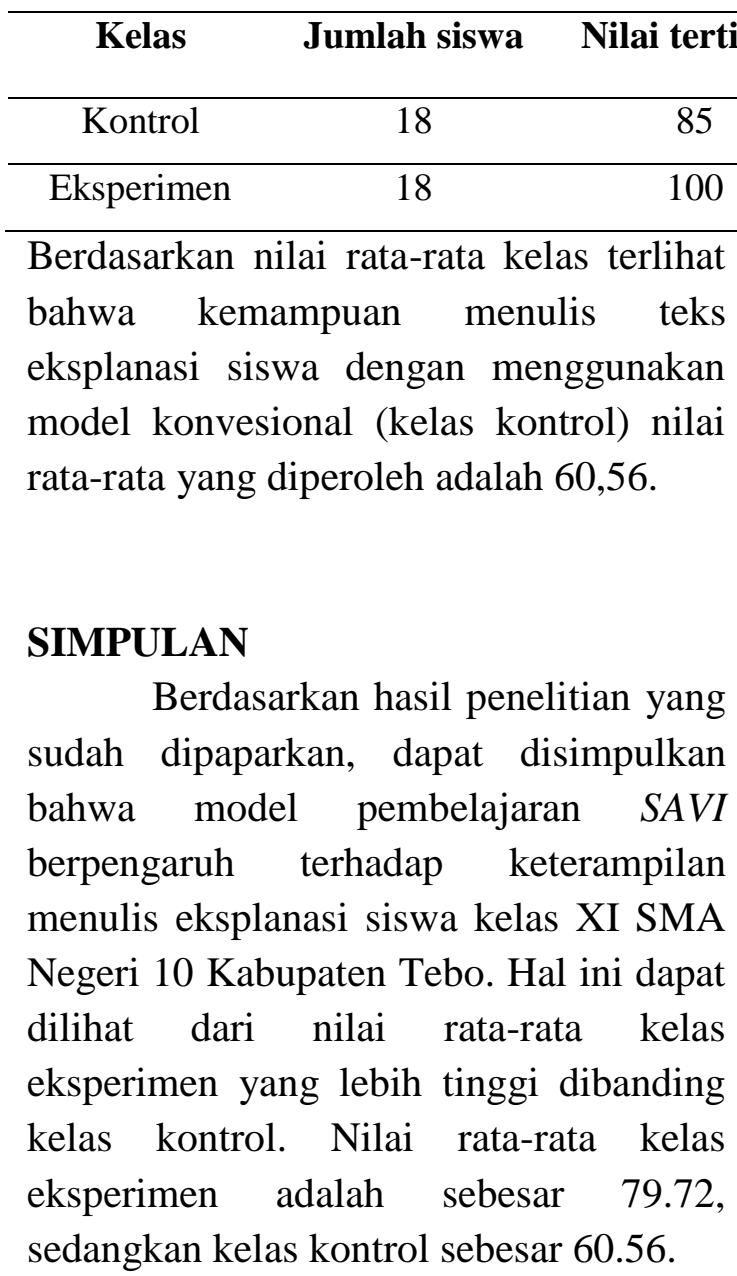

\section{DAFTAR PUSTAKA}

Abbas, Saleh. (2006). Pembelajaran Bahasa Indonesia yang Efektif di Sekolah Dasar. Jakarta: Departemen Pendidikan Nasional Direktorat Jenderal Pendidikan Tinggi Direktorat Ketenagaan.

Arikunto, Suharsimi. (2014). Prosedur Penelitian: Suatu Pendekatan Praktik. Jakarta: Rieneka Cipta.

Dalman. (2013). Keterampilan Menulis. Jakarta: Rajawali Pers.

\section{Nilai terendah Simpangan baku Rata-rata}

\begin{tabular}{lll}
25 & 15.42 & 60,56 \\
\hline 50 & 16,22 & 79,72
\end{tabular}

Damiyati dan Mudjiono. (2013). Belajar

dan Pembelajaran. Jakarta: Rieneka Cipta

Darmawati, Uti. (2018). Eksplanasi. Surakarta: Aksarra Sinergi Media.

Depdiknas. (2009). Pembelajaran Menulis. Jakarta: Pemberdayaan Pendidik dan Tenaga Kependidikan Bahasa

Faturrohman, Muhammad. (2015). Model-model Pembelajaran Inovatif. Yogyakarta: Ar-Ruzz Media.

Huda, Miftahul. (2016). Model-Model Pengajaran dan Pembelajaran. Yogyakarta: Pusat Pelajar.

Ihsan, Fuad. (2005). Dasar-dasar Pendidikan. Jakarta: Rieneka Cipta.

Kemendikbud. (2013). Bahasa Indonesia Ekspresi Diri dan Akademik. Jakarta: Balitbang, Kemendikbud.

Kosasih, E. (2017). Bahasa IndonesiaStudi dan Pengajaran. Jakarta: Kementrian Pendidikan dan Kebudayaan.

Meier, Dave. (2004). The Accelerated Learning, edisi IV. Terjemahan Hernowo, Bandung: Kaifa, Mizan Pustaka.

Priyanti, E. T. (2014). Desain Pembelajaran Bahasa Indonesia dalam Kurikulum 2013. Jakarta: Bumi Aksara. 
Rofii, A., Murtadho, F., Rahmat, A. (2018) "Model of ContextualBased Academic Writing Learning Module (R\&D At Faculty of Teacher Training And Education Universitas Batanghari Jambi)" English Review: Journal of English Education, vol. 6, no. 2 pp 5160. Doi: 10.25134/erjee.v6i2.1242.

Rofii, A., Murtadho, F., Rahmat, A. (2019 C) "The Effectiveness of Contextual-Based Academic Writing Learning Model. Asian ELF Journal.Volume 23. Issue 6.3 November 2019.

Rofii, Afif., Fathiaty, Murtadho., Rahmat, Aceng. $\quad(2019$ A). Needs Analysis: A Learning Model for CTL-Based Academic Writing. Proceedings of the Eleventh Conference on Applied Linguistics (conaplin 2018)

Rofii, Afif., Murtadho, Fathiaty., Rahmat, $\begin{array}{ll}\text { Aceng. } \quad(2019 & \text { B). The }\end{array}$ Perception of Lecturers and Students on Learning Model of Contextual-Based Academic Writing. Proceeding First International Conference on Advances in Education, Humanities, and Language. Malang: EAI

Sugiyono. (2014). Metode Penelitian Pendidikan Pendekatan Kuantitatif, Kualitatif, dan $R \& D$. Bandung: Alfabeta. 